\title{
Phylogenetic Analysis of the Synnema-Producing Genus Synnemapestaloides
}

\author{
Kyoko Watanabe ${ }^{1,2,3, *}$, Mao Sekiguchi ${ }^{2}$, Toyozo Sato ${ }^{4}$, Tom Hsiang ${ }^{5}$, Shigeru Kaneko ${ }^{4}$, \\ Kazuaki Tanaka ${ }^{6}$, Masaru Kanda ${ }^{7}$, Naoko Fujita ${ }^{8}$ and Shunsuke Nozawa ${ }^{2}$ \\ 1 Faculty of Agriculture, Tamagawa University, 6-1-1 Tamagawa-gakuen, Machida, Tokyo 194-8610, Japan \\ 2 Graduate School of Agriculture, Tamagawa University, 6-1-1 Tamagawa-gakuen, Machida, Tokyo 194-8610, \\ Japan; ma000.sanns@gmail.com (M.S.); nzwsh1ba@agrs.tamagawa.ac.jp (S.N.) \\ 3 Mycology \& Metabolic Diversity Research Center, Tamagawa University, 6-1-1 Tamagawa-gakuen, Machida, \\ Tokyo 194-8610, Japan \\ 4 Genetic Resources Center, National Agriculture and Food Research Organization, 2-1-2 Kannondai, Tsukuba, \\ Ibaraki 305-8602, Japan; s1043@gene.affrc.go.jp (T.S.); skaneko@a.email.ne.jp (S.K.) \\ 5 Environmental Sciences, University of Guelph, Guelph, ON N1G 2W1, Canada; thsiang@uoguelph.ca \\ 6 Faculty of Agriculture and Life Sciences, Hirosaki University, 3 Bunkyo-cho, Hirosaki, Aomori 036-8561, \\ Japan; k-tanaka@hirosaki-u.ac.jp \\ 7 Green Doctors, 1-10-13-201 Sagamihara, Chuoku, Sagamihara, Kanagawa 252-0231, Japan; \\ kanda-m@bp.iij4u.or.jp \\ 8 Laboratory of Plant Pathology, Graduate School of Agriculture, Tokyo University of Agriculture and \\ Technology, 3-5-8 Saiwaicho, Fuchu, Tokyo 183-8509, Japan; afujita@cc.tuat.ac.jp \\ * Correspondence: wkyoko@agr.tamagawa.ac.jp; Tel.: +81-42-739-8247
}

Academic Editor: David S. Perlin

Received: 1 September 2016; Accepted: 1 November 2016; Published: 7 November 2016

\begin{abstract}
Synnemapestaloides rhododendri, the type species of the genus Synnemapestaloides, is a pathogen of Rhododendron brachycarpum. This fungus produces six-celled conidia with appendages at both end cells, and are generated by annellidic conidiogenous cells on the synnema. These conidial structures are similar to those of the genus Pestalotia. The monotypic genus Synnemapestaloides is currently classified in the family Amphisphaeriaceae solely based on conidial morphology. Here we demonstrate that Synnemapestaloides represents a distinct genus in the family Sporocadaceae (Amphisphaeriales) based on differences in the nucleotide sequences of the partial large subunit rDNA gene, the rDNA internal transcribed spacer, and the partial $\beta$-tubulin. The genus most closely related to Synnemapestaloides is Seimatosporium and the species most similar to Synnemapestaloides rhododendri is Seim. foliicola which produces short synnema-like conidiomata (sporodochia). These results demonstrate that Seim. foliicola should be transferred to Synnemapestaloides, and also demonstrate that Sporocadaceae can have synnematal in addition to pycnidial and acervular conidiomata.
\end{abstract}

Keywords: Amphisphaeriales; conidiomatal development; Sporocadaceae; Synnemapestaloides

\section{Introduction}

Pestalotioid fungi belong to genera such as Pestalotia, Pestalotiopsis, Monochaetia, and Seimatosporium, among others. These genera are characterized by septate conidia with appendages that are apical, basal, or both, which are produced from annellidic conidiogenous cells lining the upper and inner layer of acervuli and pycnidia [1,2]. Because of the presence of acervuli or pycnidia, these fungi are all considered coelomycetes. Their formal classification as genera in Sporocadaceae is supported by similarities among sequences of their nuclear ribosomal RNAs [3-8].

Synnemapestaloides rhododendri T. Handa \& Y. Harada was isolated from twig blight of Rhododendron brachycarpum D. Don ex G. Don. It was described as a new genus and species by Handa et al. [9], 
and has only been found in Japan. The conidia of this fungus are six-celled, including four pigmented median cells, and have branched appendages at the distal and basal cells. Thus, conidial morphology is the same as that of the genus Pestalotia [10]. The presence of percurrently extending conidiogenous cells is an ontogenetic pattern common among pestalotioid fungi. The major phenotypic difference between Synnemapestaloides and Pestalotia is their conidiomatal morphology, Synnemapstalotiopsis produces synnemata and Pestalotia produces acervuli.

Hyde et al. [11] published a list of anamorphic names and, without further explanation, placed Synnemapestaloides in the family Amphisphaeriaceae together with pestalotioid fungi. However, the name Synnemapestaloides has not been used in research on pestalotioid fungi since then, and it has not been included in subsequent phylogenetic analyses. Jaklitsch et al. [8] transferred pestalotioid fungi to the Sporocadaceae from Amphisphaeriaceae except for Synnemapestaloides. Synnemapestaloides may belong in the Sporocadaceae; however, more information and evidence is needed to properly place this genus-Synnemapestaloides may belong to the Amphisphaeriaceae, Sporocadaceae, or another family, but clear evidence is still lacking. There are no synnematal fungi known in the Amphisphaeriaceae nor in the Sporocadaceae.

To define the phylogeny of Synnemapestaloides, we analyzed the nucleotide sequences encoding the partial large subunit rRNA gene (LSU), the internal transcribed spacer (ITS), and a portion of $\beta$-tubulin, and additionally conducted morphological analyses. The relationship between Synnemapestaloides and other pestalotioid fungi is discussed here.

\section{Materials and Methods}

\subsection{Strains}

The morphological and phylogenetic analyses included eight strains of Syn. rhododendri isolated from Rhododendron brachycarpum (including the ex-type strain) and three strains of Seimatosporium (Table 1). These strains were deposited in the herbarium of Hirosaki University (HHUF) as well as the culture collections of Tamagawa University (TAMA), Genebank Project NARO, Japan (MAFF). These strains were grown on potato dextrose agar (PDA) (Eiken, Tochigi, Japan) at $25^{\circ} \mathrm{C}$.

\subsection{DNA Extraction and Polymerase Chain-Reaction (PCR)}

DNA from each fungal strain was extracted from one-week-old PDA cultures using a Qiagen DNA Mini Kit (Qiagen, Tokyo, Japan) following the manufacturer's protocol. The genes amplified with these PCR primers: (1) 650 bp of the LSU (D1-D2 region) with primers NL1 and NL4 [12]; (2) ca 540 bp of the ITS with primers ITS4 and ITS5 [13]; and (3) 490 bp of $\beta$-tubulin with primers BT2a and BT2b [14]. PCR products were purified using ExoSAP-IT reagent (GE Healthcare Japan, Tokyo, Japan) and sequenced using an ABI 310 DNA sequencer (ABI, Tokyo, Japan). These sequences were deposited in the DNA Data Bank of Japan (accession numbers shown in Table 1).

\subsection{Molecular Phylogeny}

To compare amplicon sequences, data obtained from online sources and taxa (including Discostroma, which is the sexual morph of Seimatosporium) were mainly chosen from previous research on phylogeny of Pestalotioid fungi such as Jaklitsch et al. [8] and Tanaka et al. [6] (Table 1). Sequences were aligned using ClustalW [15] implemented in BioEdit [16], and manually optimized. The alignments were subjected to phylogenetic analysis using MEGA software version 7 [17]. All positions containing gaps and missing data were not considered for analyses. The strength of the internal branches from the tree was tested using bootstrap analysis [18] with 1000 replications. Trees were viewed using TreeView [19], and evolutionary history was inferred using the maximum parsimony (MP) method [20]. Consistency, retention, homoplasy, and composition indices were calculated for parsimony-informative sites. 
Table 1. Strains of Synnemapestaloides rhododendri and closely related species with sequence source.

\begin{tabular}{|c|c|c|c|c|}
\hline \multirow{2}{*}{ Species } & \multirow{2}{*}{ Strain } & \multicolumn{3}{|c|}{ GeneBank Accessions } \\
\hline & & ITS & LSU & $\beta$-tublin \\
\hline Synnemapestaloides rhododendri & MAFF $245156^{1}$ & $\mathrm{LC}^{2} 04755^{4}$ & LC047746 & LC047763 \\
\hline Synnemapestaloides rhododendri & MAFF 245157 & LC047756 & LC047747 & LC047764 \\
\hline Synnemapestaloides rhododendri & MAFF 245158 & LC047754 & LC047745 & LC047762 \\
\hline Synnemapestaloides rhododendri & MAFF 243052 & LC047757 & LC047748 & LC047765 \\
\hline Synnemapestaloides rhododendri & MAFF 243053 & LC047758 & - & LC047766 \\
\hline Synnemapestaloides rhododendri & MAFF 243054 & LC047759 & - & LC047767 \\
\hline Synnemapestaloides rhododendri & TAMA $492^{2}$ & LC047760 & LC047749 & LC047768 \\
\hline Synnemapestaloides rhododendri & MAFF $239201 *$ & LC047753 & LC047744 & LC047761 \\
\hline Bartalinia laurina & HKUCC 6537 & AF405302 & AF382369 & -5 \\
\hline Bartalinia pondoensis & CMW 31067 & GU291796 & GU291796 & - \\
\hline Bartalinia robillardoides & CBS 122705 & KJ710460 & KJ710438 & - \\
\hline Broomella vitalbae & $\mathrm{BV}=\mathrm{CBS} 140412$ & КT949895 & KT949895 & - \\
\hline Discosia aff. pleurochaeta & MAFF 242779 & AB594781 & AB593713 & - \\
\hline Discosia artocreas & NBRC 8975 & AB594773 & AB593705 & - \\
\hline Discosia pini & MAFF 410149 & AB594776 & AB593708 & - \\
\hline Discosia pleurochaeta & MAFF 242778 & AB594777 & AB593709 & - \\
\hline Discosia tricellulare & NBRC 32705 * & AB594796 & AB593728 & - \\
\hline Discosia yakushimense & MAFF $242774 *$ & AB594789 & AB593721 & - \\
\hline Discostroma tostum & NBRC 32626 & AB594795 & AB593727 & - \\
\hline Hymenopleella hippophaeicola & $\mathrm{LH}=\mathrm{CBS} 140410$ & КT949901 & КT949901 & - \\
\hline Immersidiscosia eucalypti & MAFF 242781 & AB594793 & AB593725 & - \\
\hline Lepteutypa fuckelii & $\mathrm{RS}=\mathrm{CBS} 131707$ & KT949902 & KT949902 & - \\
\hline Lepteutypa sambuci & LEF $=$ CBS 140409 & KT949904 & КT949904 & - \\
\hline Monochaetia kansensis & PSHI2004Endo1030 & DQ534044 & DQ534035 & - \\
\hline Neoestalotiopsis protearum & CBS 114178 & JN712498 & JN712564 & - \\
\hline Neopestalotiopsis rosae & CBS 101057 & KM199359 & KM116245 & - \\
\hline Pestalotiopsis knightiae & CBS 114138 & KM199310 & KM116227 & - \\
\hline Pestalotiopsis malayana & CBS 102220 & KM199306 & KM116238 & - \\
\hline Phlogicylindrium uniforme & CBS 131312 & JQ044426 & JQ044445 & - \\
\hline Pseudopestalotiopsis cocos & CBS 272.29 & KM199378 & KM116276 & - \\
\hline Robillarda africana & CBS 122.75 & KR873253 & KR873281 & - \\
\hline Robillarda sessilis & CBS 114312 & KR873256 & KR873284 & - \\
\hline Seimatosporium biseptatum & СРС 13584 & JN871199 & JN871208 & - \\
\hline Seimatosporium foliicola & NBRC $32676^{3}$ & AB593734 & AB594802 & LC047769 \\
\hline Seimatosporium hakeae & NBRC 32678 & AB594804 & AB593736 & - \\
\hline Seimatosporium obtusum & CPC $12935 *$ & JN871206 & JN871215 & - \\
\hline Seimatosporium pistaciae & CBS 138865 & P004463 & КР004491 & - \\
\hline Seimatosporium botan & NBRC $104200 *$ & AB594799 & AB593731 & LC047770 \\
\hline Seimatosporium discosioides & NBRC 104201 & AB594800 & AB593732 & LC047771 \\
\hline Seimatosporium eucalypti & CBS 115131 & JN871200 & JN871209 & - \\
\hline Seimatosporium hypericinum & NBRC 32647 & AB594805 & AB593737 & - \\
\hline Seimatosporium mariae & NBRC 32681 & AB594807 & AB593740 & - \\
\hline Seimatosporium parasiticum & NBRC 32682 & AB594805 & AB593741 & - \\
\hline Seiridium marginatum & $\mathrm{BLO}=\mathrm{CBS} 140403$ & KT949914 & KT949914 & - \\
\hline Seiridium phylicae & СРС 19965 & КC005787 & КC005809 & - \\
\hline Strickeria kochii & $\mathrm{C} 138$ & KT949917 & KT949917 & - \\
\hline Truncatella hartigii & CBS 118148 & DQ278913 & DQ278928 & - \\
\hline Zetiasplozna acaciae & CBS 137994 & KJ869149 & KJ869206 & - \\
\hline
\end{tabular}

*: EX-holotype culture, ${ }^{1}$ : MAFF: Genbank Project NARO, Japan; ${ }^{2}$ : TAMA: Culture collection of Tamagawa University; ${ }^{3}$ : NBRC: Biological Resource Center, NITE, Japan; ${ }^{4}$ : Accessions in bold were sequenced in this study; ${ }^{5}$ : This is not available; ITS: the internal transcribed spacer; LSU: the partial large subunit rRNA gene. Accession number in Bold were obtained in this study.

MP trees were generated using the Subtree-Pruning-Regrafting algorithm [20] and search level 5, which generates initial trees by randomly adding sequences (10 replicates). Molecular analyses using the maximum likelihood (ML) method were performed The $T 92+G+I$ nucleotide substitution model based on the Tamura three-parameter model [21] for ITS plus LSU phylogenetic analysis and the Kimura two-parameter method [22] for ITS plus $\beta$-tubulin analysis. Initial trees for the heuristic 
search were automatically generated by applying the neighbor-joining (NJ) and BioNJ algorithms to a matrix of pairwise distances estimated using the maximum composite likelihood approach and then selecting the topology with a higher log-likelihood value. Evolutionary history was inferred using the NJ method [23]. The tree was drawn to scale with branch-length units equivalent to those of the evolutionary distances used to infer phylogeny. Evolutionary distances were computed using the Kimura two-parameter method [22] and are expressed as the number of base substitutions per site.

To generate phylogenies based on ITS plus LSU sequences, Lepteutypa fuckelii, Lepteutypa sambuci, and Phlogicylindrium uniforme which are members of Amphisphaeriaceae (outgroup) and Phlogicylindriaceae and were chosen since they are phylogenetically close to Sporocadaceae [8]. For phylogenies assessed using ITS and $\beta$-tubulin sequences that included a more limited selection of taxa, Discosia artocreas (Tode) Fr. served as the outgroup. The data of trees are deposited in TreeBase (S19936 for ITS + LSU, S19927 for ITS + $\beta$-tubulin).

\subsection{Morphological Observations}

Eight strains of Syn. rhododendri were cultured for $30 \mathrm{~d}$ at room temperature on PDA containing the leaves of H. macrophylla [24]. Light microscopy (B51, Olympus Tokyo, Japan) was used to assess characteristics of conidia.

A stereomicroscope (WILD10; Leica Geosystems, Tokyo, Japan) was used to observe the development of conidiomata on a simple agar medium amended with a leaf piece of $H$. macrophylla. Specimens were fixed with a modified method [24] before analysis by scanning electron microscopy. Conidiomata were soaked in $0.2 \%$ osmium tetroxide for $1 \mathrm{~h}$ at $4{ }^{\circ} \mathrm{C}$, washed with $0.2 \mathrm{M}$ phosphate buffer ( $\mathrm{pH} 7.2$ ), and resoaked in $0.2 \%$ glutaraldehyde overnight at $4{ }^{\circ} \mathrm{C}$. These specimens were washed again in $0.2 \mathrm{M}$ phosphate buffer and dehydrated using an ethanol series. They were then critically dried using an Eiko DX-1 apparatus (Eiko, Tokyo, Japan), coated with gold using a JEOL JFC 1100 sputtering system (JEOL, Tokyo, Japan), and examined using a scanning electron microscope (JEOL 5200, JEOL, Tokyo, Japan) at $20 \mathrm{kV}$.

\section{Results}

\subsection{Phylogenetic Analysis of the ITS and LSU D1-D2 Region}

Thirty-six strains of pestalotioid fungi, including one preserved and five fresh strains of Syn. rhododendri, were examined (accession numbers shown in Table 1). The sequence matrix used for phylogenetic analyses contained $575 \mathrm{bp}$ from ITS and $542 \mathrm{bp}$ from LSU. Each analysis included at least 949 nucleotide positions ( $416 \mathrm{bp}$ of ITS and $533 \mathrm{bp}$ of LSU), and one of the three most parsimonious trees (length $=509$, these are similar topology) of the MP tree analysis using the Subtree-Pruning-Regrafting is shown in Figure S1A. The consistency, retention, and composite indices were $0.454,0.783$, and 0.35th the highest log-likelihood (-4141.69), respectively. The optimal tree generated using the NJ method had a branch-length sum $=0.495$ (Figure S1B). Only the ML tree (Figure 1) is shown here, since the MP and NJ methods generated similar topologies.

The six strains of Syn. rhododendri with synnemata were placed with other pestalotioid fungi. In this family, Synnemapestaloides and Seimatosporium were in the same clade with high bootstrap support (ML/MP/NJ: 94/82/92), and Syn. rhododendri was included in a subclade with high bootstrap support as well (ML/MP/NJ: 100/97/100). The species most closely placed with Synnemapestaloides was Seim. foliicola with high support (ML/MP/NJ: 95/96/94). 


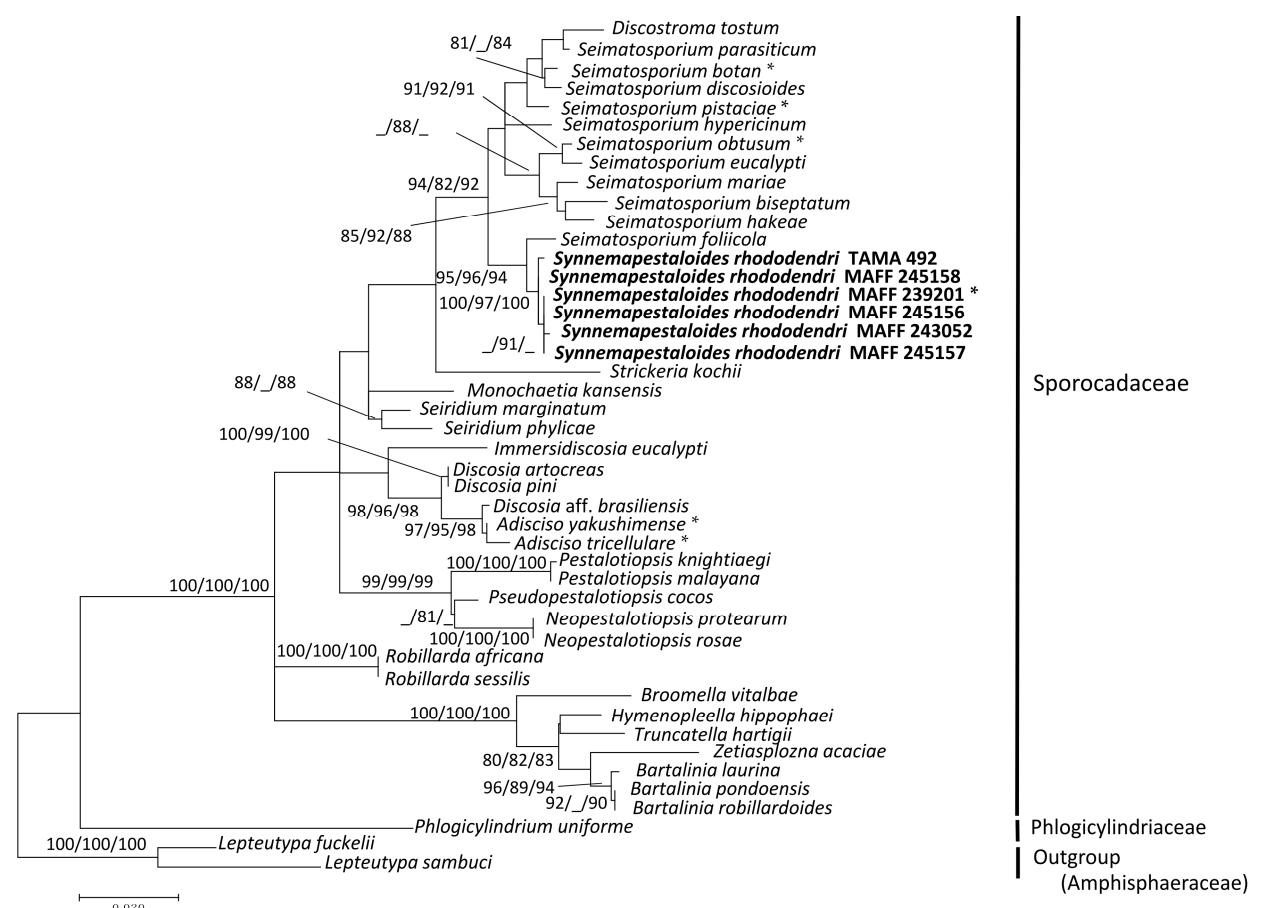

Figure 1. Maximum likelihood (ML) tree with the highest log-likelihood (-4141.69) determined by analysis of the combined ITS and LSU (D1-D2) sequence matrix. Numbers (ML/MP/NJ) and hyphens on the branches indicate the bootstrap values (\%) for each node, calculated from 1000 replicates and only values $>80 \%$ are shown. MP: maximum parsimony, NJ: neighbor-joining. *: Ex-holotype cultures. Strains in Bold were investigated in this study.

\subsection{Phylogenetic Analysis of ITS and $\beta$-Tubulin}

The sequences of eight Syn. rhododendri and three species of Seimatosporium, were selected according to the LSU phylogeny, and their ITS plus $\beta$-tubulin sequences were subjected to phylogenetic analysis using Discosia artocreas as the outgroup. The final dataset included 846 informative positions (522 bp of ITS and $335 \mathrm{bp}$ of $\beta$-tubulin). The branch length of the NJ tree based on the analyses of ITS and $\beta$-tubulin was 0.227 (Figure S2B), and the highest log-likelihood of the phylogenetic tree generated using the ML method was -2131.68 (Figure 2). Using the MP method, a single most parsimonious tree was obtained with a tree length of 194 steps, and the consistency, retention, and composite indices were $0.832,0.848$, and 0.705 , respectively, for parsimony-informative sites. The MP tree is shown in Figure S2A.

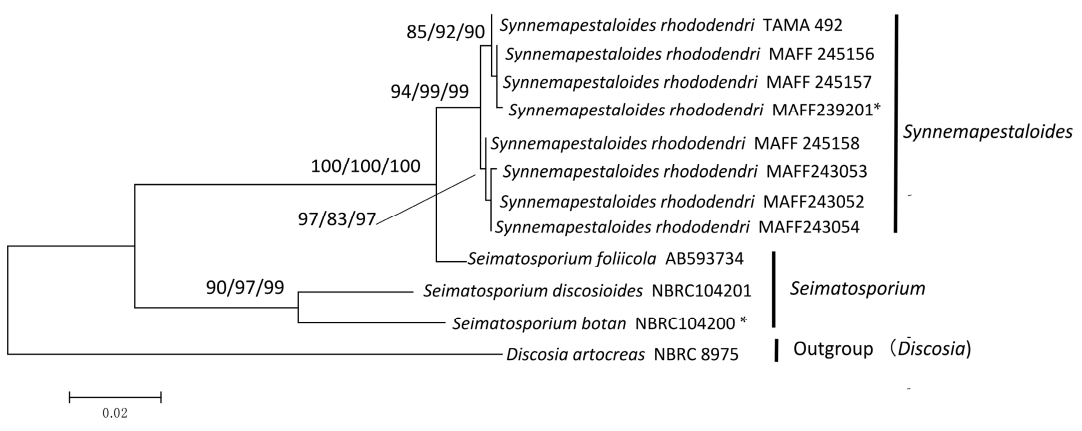

Figure 2. Maximum likelihood (ML) tree with the highest log-likelihood (-2131.68) determined by analysis of the combined ITS and $\beta$-tubulin sequence matrix. The numbers (ML/MP/NJ) on the branches indicate bootstrap values (\%) for each node, calculated from 1000 replicates. MP: maximum parsimony, NJ: neighbor-joining. *: Ex-holotype cultures. 
All phylogenetic trees clustered the Sporocadaceae into two clades (Figure 2). One clade comprised Syn. rhododendri and Seim. foliicola with maximum bootstrap support, with $94 \%-99 \%$ bootstrap support for the subclade comprising only Syn. rhododendri. The other highly supported clade comprised Seim. botan Sat. Hatak. \& Y. Harada and Seim. discosioides (Ellis \& Everh) Shoemaker.

\subsection{Development of Conidiomata and Conidial Structures}

The hyphal fascicles of the Syn. rhododendri strains burst through the epidermal cells of the plant leaf (MAFF 239201, Figure 3A,B; TAMA 492, Figure 3D,E). These hyphae elongated into synnematous conidiophores and produced conidia (MAFF 239201, Figure 3C; TAMA 492, Figure 3F). The ontogeny of Seim. foliicola (Figure 3G-I) was similar to that of Syn. rhododendri, except that its conidiophores were shorter (Figure 3I). Thus, the primordia of the conidiogenous cell of Seim. foliicola were not produced under the epidermal layers of the leaf (Figure 3G,H). In contrast, the conidia of Seim. botan (Figure 3J) and $S$. discoides (Figure 3M) did not appear until leaf surfaces cracked, and conidia were visible through breaks in the leaf surface (Figure 3K,L,N,O). This ontogeny is similar to those of Pestalotiopsis guepinii Desm., P. neglecta (Thüm.) Steyaert [24], and Truncatella species [25].
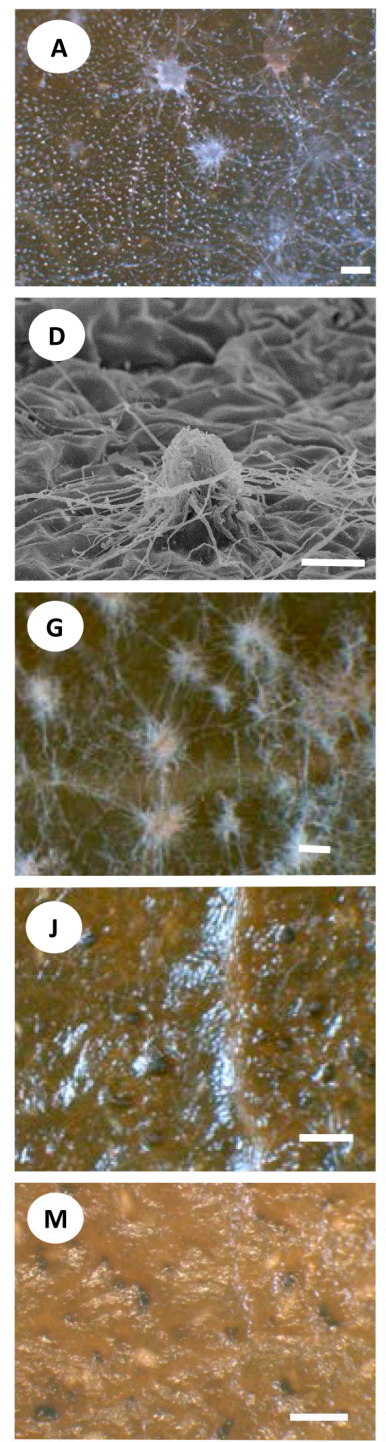
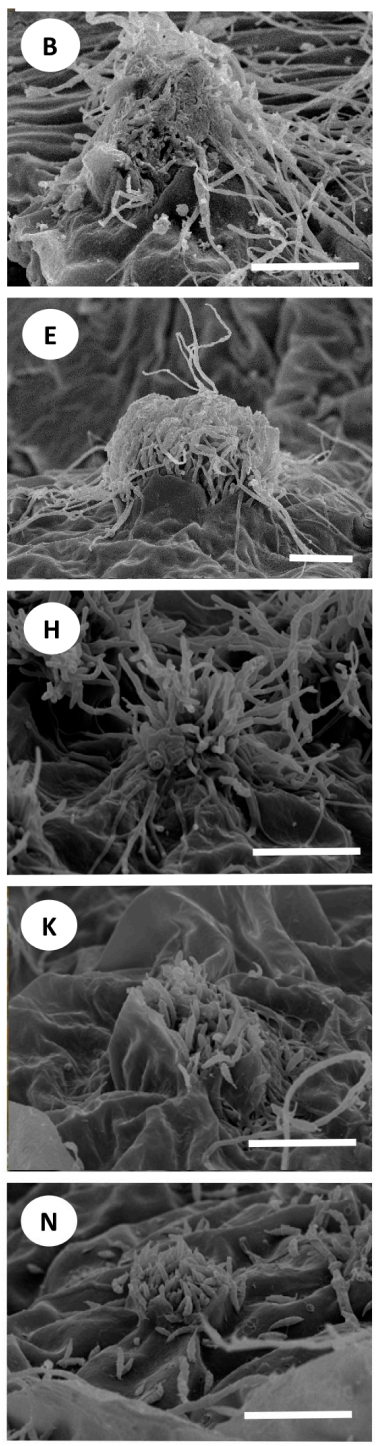
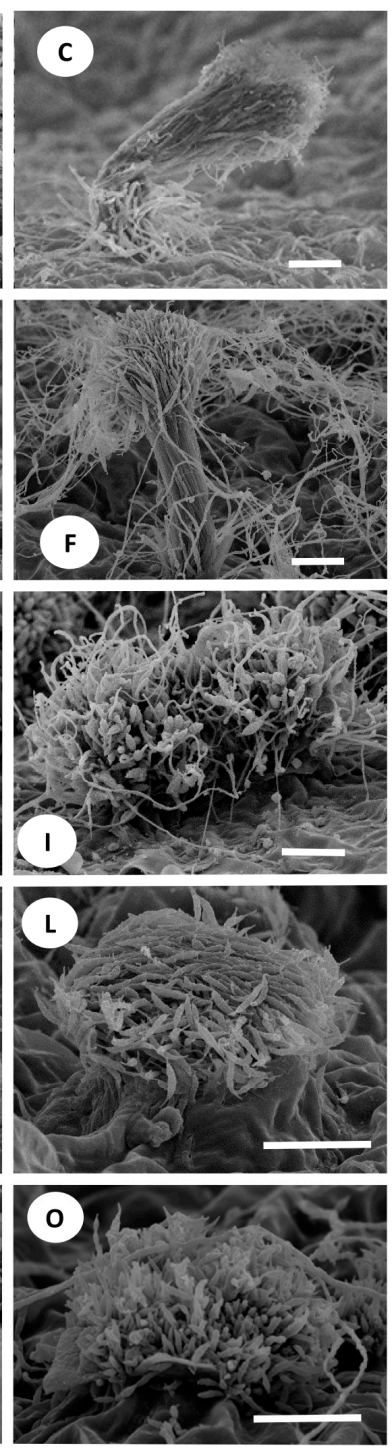

Figure 3. Ontogeny of conidiomata: (A-C) Synnemapestaloides rhododendri MAFF 239201; (D-F) Syn. rhododendri TAMA 492; (G-I) Seimatosporium foliicola NBRC 32676; (J-L) Seim. botan NBRC 104200; and (M-O) Seim. discosioides NBRC 104201. (A,G,J,M) Bars = $100 \mu \mathrm{m} ;(\mathbf{B}-\mathbf{F}, \mathbf{H}, \mathbf{I}, \mathbf{K}, \mathbf{L}, \mathbf{N}, \mathbf{O})$ Bars $=50 \mu \mathrm{m}$. 
Synnemapestaloides rhododendri and Seim. foliicola had conidia with six cells, including four pigmented median cells (Figure 4A-C). The conidia of Seim. botan (Figure 4D) and Seim. discoides had four cells, including two pigmented cells.
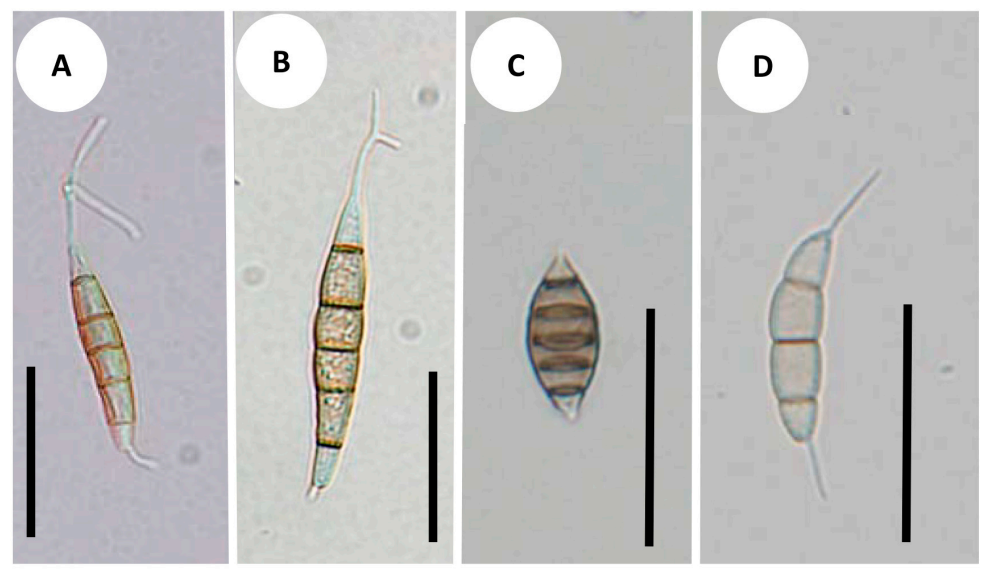

Figure 4. Conidial morphology: (A) Synnemapestaloides rhododendri MAFF 239201; (B) Syn. rhododendri TAMA 492; (C) Seimatosporium foliicola NBRC 32676; (D) Seim. botan NBRC104201. Bars = $25 \mu \mathrm{m}$.

\section{Discussion}

Pestalotioid fungi share morphological features such as the masses of annelloconidia produced from conidiogenous cells inside or on their conidiomata, which are acervuli or pycnidia. Pestalotioid conidia are fusiform, straight, or slightly curved with several septa with or without simple or branched appendages at the apical or basal cells [26]. The first described pestalotioid fungus was Pestalotia pezizoides De Not., which grows on branches of Vitis vinifera L. [10], and its conidia with six cells, are fusiform, straight, or slightly curved. The basal appendage, which grows from truncated basal cells, is endogenous, unbranched, or dichotomously branched. Apical appendages are unbranched or dichotomously branched. Subsequently, fungi with different numbers of cells and appendages were classified as Pestalotia.

Since 1948, several studies have attempted to rearrange and separate more than seven related genera based on the number of the cells of the conidia and appendages $[1,26-28]$ and variation in conidial ontogeny. Analysis of DNA sequences has also been used [3]. All morphologically related genera in this group were placed in the Amphisphaeriaceae within Amphishaeriales, but re-examination and reclassification at the genus and species levels are needed because these phylogenetic trees contained paraphyletic clades. Accordingly, Jaklitsch et al. [8] assigned this group to the Sporocadaceae within Amphishaeriales.

Synnemapstalotiopsis rhododendri and P. pezizoides produce similarly shaped conidia [9]. However, sporulation of Synnemapestaloides occurs on synnemata, and therefore the first strain that was isolated was classified as a new genus and designated as a hyphomycete [9] unlike other pestalotioid fungi which are coelomycetes. Hyde et al. [11] assigned Synnemapestaloides to the family Amphisphaeriaceae; however, this classification was not based on DNA sequence data. Since the suggestion of Hyde et al. [11], no published information has become available to confirm the inclusion of Synnemapestaloides in Amphisphaeriaceae. Here, our phylogenetic analysis assigned all strains of Synnemapestaloides and Seimatosporium to one clade, with relatively high bootstrap values (ML/MP/NJ: 94/82/92) for the phylogenetic tree obtained from the combined ITS-LSU matrix (Figure 1). The findings indicate that Synnemapestaloides belongs to the Sporocadaceae which had been separated from the Amphisphaeriaceae and mainly contain pestalotioid fungi.

In the present study, Synnemapestaloides formed a highly supported clade (ML/MP/NJ: 100/97/100) within the Seimatosporium clade, and the morphology of Synnemapestaloides was clearly 
distinguishable from that of Seimatosporium spp. The phylogenetic analyses of ITS and $\beta$-tubulin sequences (D. artocreas as the outgroup, Figure 2) allowed assignment of Syn. rhododendri and Seim. foliicola to a single clade with highest bootstrap support.

The species most closely related to Syn. rhododendri, was Seim. foliicola, and it was separated from other species of Seimatosporium, which supports the assignment of Seim. foliicola to its own genus separate from Seimatosporium. This species, which has conidia with five septa and single appendages at the apical and basal cells produced from conidiogenous cells on acervular, stromatic condiomata, is therefore grouped as the sarcostroma type [1]. The single major feature shared between Seim. foliicola and Syn. rhododendri was the cell number per conidium (Figure 4). Furthermore, we found that conidia from both fungi were produced from a structure resembling synnemata, although the lengths differed.

There are several developmental types of conidiomata [29]. Watanabe et al. [24] studied acervular development of the pestalotioid fungi Pestalotiopsis neglecta (Thüm.) Steyaert and Truncatella species. They found that the primordia of acervuli are produced as an aggregation of hyphae under the epidermis of a leaf, which develop into pycnidia-like structures that produce conidia from conidiogenous cells in the center of the cavity. The upper layer of this pycnidia-like structure is then disrupted by autolysis to form acervuli. Here we found that Seim. botan and Seim. discoides, which are grouped into Seimatosporium, produced conidia from conidiogenous cells under the epidermis, and conidia appeared when the leaf surface split (Figure 3K,N). This type of development is the same as that observed in studies of Pestalotiopsis spp. and Truncatella sp. $[24,25]$ and differs from that of Seim. foliicola.

In contrast, the majority of conidiomata of Syn. rhododendri and Seim. foliicola grew upward and produced conidia at the tip of the conidiophore as synnemata on the leaf surface. The short synnemata (sporodochia) of Seim. foliicola can be easily confused with acervuli, time-lapse observations clearly discriminated between the conidioma types between the short synnemata (Figure $3 \mathrm{H}$ ) and acervuli (Figure 3K, N). The synnemata of Seim. foliicola were shorter and wider compared with those of Syn. rhododendri, although the development of each was similar. For the clade shown in Figure 2 comprising Syn. rhododendri and Seim. foliicola, the synnema or sporodochia developing conidiophore may represent a monophyletic synapomorphic characteristic.

Seimatosporium is a large and diverse genus characterized by conidia comprising median pigmented cells with or without appendage(s). Classification within this genus has been discussed according to morphology as well as LSU and ITS sequences $[1,6,26,27,30]$. Molecular phylogenetic trees of Seimatosporium by Tanaka et al. [6] and Norphanphoun et al. [30] showed that Seim. foliicola is separated from other species. From this study, Seim. foliicola is closer to Synnemapestaloides than Seimatosporium.

In summary, we assign Synnemapestaloides to Sporocadaceae, and its most closely related genus is Seimatosporium. Molecular phylogenetic analyses and morphological analyses differentiate Seim. foliicola from other Seimatosporium species used in this study. Thus, Seim. foliicola should be transferred to Synnemapestaloides, and the formal taxonomic definition follows.

Supplementary Materials: Supplementary materials can be accessed at: www.mdpi.com/2309-608X/2/4/28/s1.

Acknowledgments: This research was supported by a grant and donation from the Institute for Fermentation, Osaka (IFO), and JSPS KAKENHI Grant Number 25440218, 26291084, and 16K07474.

Author Contributions: Kyoko Watanabe conceived and designed the experiments; Kyoko Watanabe, Mao Sekiguchi, and Shunsuke Nozawa performed the experiments; Kyoko Watanabe and Shunsuke Nozawa analyzed the data; Kyoko Watanabe, Shigeru Kaneko, Masaru Kanda, and Kazuaki Tanaka contributed materials. Kazuaki Tanaka deposited sequence data to GenBank and gave advice on revisions; Kyoko Watanabe, Toyozo Sato, Tom Hsiang, Naoko Fujita and Shunsuke Nozawa discussed and wrote the paper.

Conflicts of Interest: The authors declare no conflict of interest. 


\section{Appendix}

Taxonomy

Synnemapestaloides T. Handa \& Y. Harada emend. Kyoko Watan., Nozawa, Kaz. Tanaka \& Toy. Sato

Conidiomata synnematous or sporodochial, determinate, black, not changing color in $2 \% \mathrm{KOH}$ or $85 \%$ lactic acid, arising from a basal stroma composed of textura angularis; hyphae of stipe parallel or those of sporodochia loose; conidial mass, black, globose to subglobose, subgelatinous. Conidiophores verticillately to sublaterally branched several times. Conidiogenous cells cylindrical to subcylindrical with annellations. Conidia fusiform with a truncate base, straight, septate, light olivaceous to pale brown; apical appendage centric; basal appendage excentric.

Synnemapestaloides foliiola (Berkeley) Kyoko Watan. Nozawa, Kaz. Tanaka \& Toy. Sato comb. nov. [MB818747]

Basionym:

Podisoma foliicola Berk. in Smith The English Flora, Fungi 5-2 (2): 362 (1836).

Synonym:

EHendersonia foliicola (Berk.) Fuckel, Jahrbücher des Nassauischen Vereins für Naturkunde 23-24:

391 (1870).

$\equiv$ Cryptostictis foliicola (Berk.) B. Sutton, Mycological Papers 88: 27 (1963).

三Seimatosporium foliicola (Berk.) Shoemaker, Canadian Journal of Botany 42 (4): 416 (1964).

$\equiv$ Sarcostroma foliicola (Berk.) M. Morelet, Bulletin de la Société des Sciences Naturelles et d'Archéologie de Toulon et du Var 37 (4): 233 (1985).

ESarcostroma foliicola (Berk.) Nag Raj, Coelomycetous anamorphs with appendage-bearing conidia: 787 (1993).

\section{References}

1. Nag Raj, T.R. Coelomycetous Anamorphs with Appendage Bearing Conidia; Mycologue: Waterloo, ON, Canada, 1993.

2. Kirk, P.; Cannon, P.F.; Minter, D.W.; Stalpers, J.A. Ainsworth and Bisby's Dictionary of the Fungi, 10th ed.; CAB International: Wallingford, ON, Canada, 2008.

3. Jeewon, R.; Liew, E.C.Y.; Hyde, K.D. Phylogenetic relationships of Pestalotiopsis and allied genera inferred from ribosomal DNA sequences and morphological characters. Mycol. Res. 2002, 25, 378-392. [CrossRef]

4. Jeewon, R.; Liew, E.C.Y.; Hyde, K.D. Molecular systematics of the Amphisphaeriaceae based on cladistic analyses of partial LSU rDNA gene sequences. Mycol. Res. 2003, 107, 1392-1402. [CrossRef]

5. Lee, S.; Crous, P.W.; Wingfield, M.J.; Sacc, B. Pestalotioid fungi from Restionaceae in the Cape Floral Kingdom. Stud. Mycol. 2006, 55, 175-187. [CrossRef]

6. Tanaka, K.; Endo, M.; Hirayama, K.; Okane, I.; Hosoya, T.; Sato, T. Phylogeny of Discosia and Seimatosporium, and introduction of Adisciso and Immersidiscosia genera nova. Persoonia 2011, 26, 85-98. [CrossRef]

7. Senanayake, I.C.; Maharachchikumbura, S.S.N.; Hyde, K.D.; Bhat, J.D.; Jones, E.B.G.; Mckenzie, E.H.C.; Dai, D.Q.; Daranagama, D.A.; Dayarathne, M.C.; Goonasekara, I.D.; et al. Towards unraveling relationships in Xylariomycetidae (Sordariomycetes). Fungal Divers. 2015, 73, 73-144. [CrossRef]

8. Jaklitsch, W.M.; Gardiennet, A.; Voglmayr, H. Resolution of morphology-based taxonomic delusions: Acrocordiella, Basiseptospora, Blogiascospora, Clypeosphaeria, Hymenopleella, Lepteutypa, Pseudapiospora, Requienella, Seiridium and Strickeria. Persoonia 2016, 37, 82-105.

9. Handa, T.; Fujita, T.; Harada, Y. Synnemapestaloides rhododendri, a new genus and new species of synnematous hyphomycete, causing synnemapestaloides twig blight disease of Rhododendron brachycarpum in Japan. Mycoscience 2004, 45, 137-142. [CrossRef]

10. De Notaris, G. Micromycetes italiei Dec II. Mem. Accad. Sci. Torino 1839, 3, 80-81. 
11. Hyde, K.D.; McKenzie, E.H.C.; KoKo, T.W. Towards incorporating anamorphic fungi in a natural classification-Checklist and notes for 2010. Mycosphere 2011, 2, 1-88.

12. O'Donnell, K. Fusarium and its near relatives. In The Fungal Holomorph: Mitotic, Meiotic and Pleomorphic Speciation in Fungal Systematics; Reynolds, D.R., Taylor, J.W., Eds.; CAB International: Wallingford, UK, 1993; pp. 225-233.

13. White, T.J.; Bruns, T.; Lee, S.; Taylor, J.W. Amplification and direct sequencing of fungal ribosomal RNA genes for phylogenetics. In PCR Protocols: A Guide to Methods and Applications; Innis, M.A., Gelfand, D.H., Sninsky, J.J., White, T.J., Eds.; Academic Press: New York, NY, USA, 1990; pp. 315-322.

14. Glass, N.L.; Donaldson, G.C. Development of primer sets designed for use with the PCR to amplify conserved genes from filamentous ascomycetes. AEM 1995, 61, 1323-1330.

15. Thompson, J.; Higgins, G.; Gibson, T.J. CLUSTAL W: Improving the sensitivity of progressive multiple sequence alignment through sequence weighting, position-specific gap penalties and weight matrix choice. Nucleic Acids Res. 1994, 22, 4673-4690. [CrossRef]

16. Hall, T.A. BioEdit: A user-friendly biological sequence alignment editor and analysis program for windows 95/98/nt. Nucleic Acids Symp. Ser. 1999, 41, 95-98.

17. Kumar, S.; Stecher, G.; Tamura, K. MEGA7: Molecular evolutionary genetics analysis version 7.0 for bigger datasets. Mol. Biol. Evol. 2016, 33, 1870-1874. [CrossRef]

18. Felsenstein, J. Confidence limits on phylogenies: An approach using the bootstrap. Evolution 1985, 39, 783-791. [CrossRef]

19. Page, R.D.M. TreeView: An application to display phylogenetic trees on personal computers. Comput. Appl. Biosci. 1996, 12, 357-358.

20. Nei, M.; Kumar, S. Molecular Evolution and Phylogenetics; Oxford University Press: New York, NY, USA, 2000.

21. Tamura, K. Estimation of the number of nucleotide substitutions when there are strong transition-transversion and G + C-content biases. Mol. Biol. Evol. 1992, 9, 678-687.

22. Kimura, M. A simple method for estimating evolutionary rate of base substitutions through comparative studies of nucleotide sequences. J. Mol. Evol. 1980, 16, 111-120. [CrossRef]

23. Saitou, N.; Nei, M. The neighbor-joining method: A new method for reconstructing phylogenetic trees. Mol. Biol. Evol. 1987, 4, 406-425.

24. Watanabe, K.; Doi, Y.; Kobayashi, T. Conidiomatal development of Pestalotiopsis guepinii and P. neglecta on leaves of Gardenia jasminoides. Mycoscience 1998, 39, 71-75. [CrossRef]

25. Watanabe, K.; Kobayashi, T.; Doi, Y. Conidiomata of Truncatella sp. on different media (in Japanese). Nippon Kingakukai Kaiho 1998, 39, 21-25.

26. Sutton, B.C. The Coelomycetes: Fungi Imperfecti with Pycnidia, Acervuli and Stromata; Commonwealth Mycological Institute: Kew, UK, 1980.

27. Steyaert, R.L. Contributions à l'étude monographique de Pestalotia de Not. et Monochaetia Sacc. (Truncatella gen. nov. et Pestalotiopsis gen. nov.). Bull. Jard. Bot. Etat. Brux. 1949, 19, 285-354. [CrossRef]

28. Guba, E.F. Monograph of Pestalotia and Monochaetia; Harvard University Press: Cambridge, UK, 1961.

29. Hanlin, R.T. Conidioma development in Ophiodothella vaccinii. Mycologia 2003, 95, 506-512. [CrossRef]

30. Norphanphoun, C.; Maharachchikumbura, S.N.N.; Daranagama, D.A.; Bulgakov, T.S.; Bhat, D.J.; Bahkali, A.H.; Hyde, K.D. Towards a backbone tree for Seimatosporium, with S. physocarpi sp. nov. Mycosphere 2015, 6, 385-400.

(C) 2016 by the authors; licensee MDPI, Basel, Switzerland. This article is an open access article distributed under the terms and conditions of the Creative Commons Attribution (CC-BY) license (http://creativecommons.org/licenses/by/4.0/). 